Times, "was indicted for the wilful murder of her new-born female child, at Southampton, on the 18th of September last.-Mr. Saunders conducted the case on the part of the prosecution; Mr. Missing for the prisoner." Several witnesses were examined for the prosecution, and, after a trial of seven hours, the jury returned a verdict of "Not guilty of the mirder," but "guilty of the concealment," and she was sentenced to three months imprisonment. At the close 'of the report, the writer of the statement adds the following observations :-

"One thing is worthy of remark. The surgeon who was furst called in, and who examined the person of the prisoner, and the child, afterwards presided as coroner at the inquest sitting on the body of the child, when the jury returned a vertict of ' wilful murder,' and he eventually gave evidence against her on the trial, having previously acted as julge in the case. Without, in the slightest degree, casting any imputation on this gentleman, we cannot but consider this as a state of things which ought not to exizt, and it is a very strong argument againet the appointment of medical coroners."

The "argument" which the writer, - a barrister, most probably,-suggests in this case, as showing the impropricty of appointing medical men to fill the office of coroner, is exactly such an one as we should expect to hear, not from an intelligent reasoner, but from a parchment-headed scribbler. Did it not oceur to him that medical coroners might not be engaged in medical practice, and that it is in the power of the law to institute such a protection, if it be a wise one? But, as a lawyer, he ought to have known that the medical coroner in the case in question had no alternative. Having attended the prisoner in the course of his practice, how could he conjecture, before the result was known, that an inquest would be necessary? And when it was deemed ne. cessary, for the ends of public justice, that an inquest should be held, then he was obliged to act as coroner, because it was not in his power to appoint a deputy. No imputation whatever, therefore, can be justly cast upon the coroner, for acting as he did at the inquest, aurl at the trial in question. That the law is loose, and most imperfect with regard to the office of coroner, gcnerally, we willingly confess; but, bctore it is mended, it must find other correctors than the sapient critic of The Times.
Coniom Maculatum. - At the last meet: ing of the Medico-Botanical Society, Dr. Sig. mond made some observations on the most eligible method of drying and preparing the leaves of conium maculatum for medicinal use. The leaves being in a high state of preservation, and entirely freed from their stalks, and as much as possible from external moisture, they should be laid in thin layers on willow baskets, stripped of the bark. They must be placed in a room from which all light is excluded, and then submitted for three or four hours to a heat of a iittle below $212^{\circ}$ of temperature. Having been then turned, they should be exposed to the same heat for about eight hours. They are then crumbled by the hand, with great facility, into a fine powder. Dr. Sigmond showed a good specimen of the powder prepared in this way. Dr. S. considered that the autumnal season was the best for gather: ing the leaves.

Impure Castor Ort.-Dr. Sigmond also cautioned the profession against a fraud which had been extensively practised by a company who had invented a process, by which rancid and ineffective castor oil could be inade apparently sweet and good. It is, however, pcrfectly useless, and possesses no purgative power. Great quantities have been disposed of, and he thought well that the system should be exposed.

\section{MEDICAL WITNESSES' PETITIONS.}

\section{To the Editor of The Lancet.}

Sir: The members of the medical pro. fession must be much gratified at the man. ner in which the announcement was received by the House, on 'Tuesday evening, the 1st instant, of your intention to intro. duce a Bill for granting rentuoration to medical witnesses, for their attendance at coroners' inquests. The subject was introduced at the monthly meeting of the medical society of this city, on Friday evening last, and a commitree was appointed for the purpose of drawing up petitions to both Houses of Pariament, which they have done, and they will probably be signed by all the medical men in the cify and neigh: bourhood. Enclosed is a copy fur publication in your widely circulated journal, should you consider that its appearance would excite others to follow our example. The favourable reception of the motion for leave to bring in the Bill, does not justify us, in my opinion, in relying upon the first success of the Bill, but it becomes the duty of every member of the profession instantly to entbody his sentiments in a petition, and forward it to the only quarter for redress. I am, Sir, in haste, yours, \&c.

3, New Kaing-st., Bath, March 9, 1836 . 
** In another part of this week's LANcer' we hare inserted a copy of the carliest petition received this week, and that we trust will serve tho same umpose as would the insertion of the petition forwarded by Mir. King, and many others with the same inportant prayer, which we have within the last few days received from medical gentle. men in different parts of the kingiom.

LATE ADDRESS TO APOTHECARIES' HALL.

\section{To the Elitor of The LanceT.}

SIR: I was truly astonished to learn how chicken-hearted the students of the London Uninersity harl become when they sent their addiress to the Hall. I thought they possessed more conrage and more knowlenge than to fear the Rhubarbians. How are the vaunted fallen! How have the students of my alma mater degenerated! In days gone by, no document would have been signed and forwarded to the Blackfriars estabiishment with any evidences of fear or want of favour. The students would have had more corifidence in their abilities and acquirements, than to bow and pray for mercy before $\mathrm{Ri}$ dout and Co.

I perceive in the list some names of 1832 men. $M^{* *} \mathrm{rh}^{* *} \mathrm{~d}, \mathrm{~W}^{*} \mathrm{k}^{* * *} \mathrm{ld}$, and others, I blush for you. Among others I see J. D*r. *nc*. Are you afraid, too? "Tell it not in Gath." I am, Sir, yours, An Old Student in the March 7, 1836. Provinces.

\section{METROPOLITAN INFIRMARY FOR CHILDREN,} Broad street, Golden-square.

MEASLES FOLLOWING CROUP.

George Coopre, aged 5, a remarkably fine and robust boy, was entered as a patient under Dr. TweEdoale, on Monday the $29 \mathrm{th}$ of February last. The little patient was labouring under the frequent, dry, hoarse cough which is pecuiliar to croup. His skin was hot and dry; the face flushed; the eyes suffused; the tongue white and furred; pulse 130, full; bowels costive; he complains of headache and lassitude. Mis mother states that on pratting him to bed on Saturday evening she noticed that he had a hard dry cough; he was very feverish all day on Sunday, and in the evening she procured some medicine for him, which made him very sick. Five leeches were applied immediately to the throat, and three grains of calomel, and five of powdered scaminony, were given every two hours until the bowels were well purged, and a tablespoonful of a mixture containing liquor antim. tart., and oxymel of squills, of each five drachms, and four ounces of saline mixture, were ordered every two hours.

Vesper..-The leeches have bled freely; the bowels have been well opened; he has vomiced, several times, a quantity of thick mucus, with small portions of fibrine. Two grains of calomel and three of James's powder, were ordered to be given every four hours. The mixture to be continued. To be put into a warm-bath up to the hips.

March 1. Still feverish; pulse 110, and small; cough much relieved. The surface is covered with the eruption of measles. Three grains of calomel and six of scammony powder, ordered to be taken directly. The other medicine to be continued.

2nd. Fever much abated; bowels do not keep open without medicine; pulse 100 , small; cough still troublesome, though there is not so much expectoration; the eruption is developed more fully; he is able to sit up in bed; a blister was applied to the chest, and a purgative was given night and morning. The powders and mixture discontinued. He continued to improve, and is now convalescent.

This is the second case, in the infirmary, of croup followed by measles, terminating favourably under the same plan of treatment. The first patient was a healt hy boy, eight years of age, who was bled from the arm, and had leeches to the throat.

\section{ST. BARTHOLOMEW'S HOSPITAL.}

Tumovr on The SCAPUla.-James Jackson was brought into the hospital with a large tumour, occupying the left scapular region, of about the size of two-thirds of a large melon. A tumour of about half that size had been removed, five months previous, from underneath the scapula, by Mr. EARxe, but the disease returned, and increased to the above magnitude, continuing rapidly to enlarge up to the day of the operation. From the condition of the old cicatrix it was by some authorities deemed malignant. The operation was performed by Mr. SkEY. The man, after some loss of time occupied in determining his position, was finally placed in the re. cumbent posture on the operating-table, lying nearly on his face. The opcration was commenced by an incision, forming a part of a small fiap, reflected towards the shoulder, which exposed the spine of the scapula, orer the line at which it was afterwards divided. Two other large dlaps were made, each forming nearly a semicircle; the one directed npwards towards the side of the neck, the other downwards. All the muscles of the dorsum of the scapula weré 